\title{
A study on $\mathrm{Pb}$ removal kinetics using modified agricultural wastes from Tanzania
}

\author{
Mwemezi Johaiven Rwiza' ${ }^{1} \cdot$ Matthias Kleinke ${ }^{2} \cdot$ Kyoung-Woong Kim³ ${ }^{3}$
}

Received: 16 August 2020 / Accepted: 20 October 2020 / Published online: 29 October 2020

(c) Springer Nature Switzerland AG 2020

\begin{abstract}
Lignocellulosic materials, abundant and renewable materials, are gaining popularity as metal scavenging agents because of their high sorption capacities, relatively low cost and environmental-friendliness. However, there is not much research to discover how the modification of different lignocellulosic materials can enhance their metal sorption capacities. In the present study, corn hulls and rice husks were pyrolyzed at $500^{\circ} \mathrm{C}$ to produce biochars and these biochars were then activated using $\mathrm{KOH}$ and $\mathrm{ZnCl}_{2}$ as activating agents. Material characterization was done using Field Emission-Scanning Electron Microscope (FE-SEM), Brunauer-Emmett-Teller (BET) analysis, and Fourier Transform Infrared (FTIR) analysis. Equilibrium concentrations were measured using Inductively Coupled Plasma-Optical Emission Spectrometry (ICP-OES). Results indicated that the modified biosorbents removed $\mathrm{Pb}^{2+}$ more efficiently and faster than the raw hulls and husk. The $\mathrm{KOH}$-treated corn husk biochar (KOH-CHB) achieved a removal capacity of $>97 \mathrm{mg} / \mathrm{g}$ in the first $15 \mathrm{~min}$ compared to a sorption capacity of $15 \mathrm{mg} / \mathrm{g}$ achieved by raw corn husk $(\mathrm{CH})$. High $\mathrm{Pb}^{2+}$ removal by activated biochars at a relatively shorter contact time was probably attributable to enhanced structures as indicated in the FT-IR, SEM, and BET results. The results also indicated that, for all eight biosorbents, the removal of $\mathrm{Pb}^{2+}$ from water followed a pseudo-second-order kinetic model with $R^{2}$ values $>0.94$. This model was able to predict the experimental $q_{e}$ values with greater precision than the pseudo-first-order kinetic model. Low-cost materials used in the current study have the potential to remove toxic $\mathrm{Pb}^{2+}$ from water and this $\mathrm{Pb}^{2+}$ removal can be attained at a relatively low cost.
\end{abstract}

Keywords Agro-industrial wastes · Metal sorption capacities · Biosorption kinetics · Pseudo-first-order kinetic model · Tanzanian lignocellulosic materials

\section{Introduction}

Toxic metal and metalloid ions in the environment are a global challenge to environmental engineers, environmental scientists, water treatment specialists, biologists, life scientists and even soil scientists. Because of their toxicity, non-biodegradability, and persistence, these ions require strict special monitoring and control measures. The following are some of the negative human and/or ecological health effects of several metal or metalloid ions: $\mathrm{Pb}^{2+}$ is known as neurotoxin especially in underage children; $\mathrm{Ni}^{2+}, \mathrm{Be}^{2+}, \mathrm{As}^{3+}, \mathrm{Cd}^{2+}$, and $\mathrm{Cr}^{6+}$ are known as carcinogens;

Supplementary information is available for this paper at https://doi.org/10.1007/s42452-020-03743-6.

Mwemezi Johaiven Rwiza, mwemezi.rwiza@nm-aist.ac.tz; Matthias Kleinke, matthias.kleinke@hochschule-rhein-waal.de; Kyoung-Woong Kim, kwkim@gist.ac.kr| ${ }^{1}$ School of Materials, Energy, Water and Environmental Studies (MEWES), The Nelson Mandela African Institution of Science and Technology (NM-AIST), P.O. Box 447, Arusha, Tanzania. ${ }^{2}$ Faculty of Life Sciences, Rhine-Waal University of Applied Sciences, Campus Kleve, Marie-Curie-Straße 1, 47533 Kleve, Germany. ${ }^{3}$ School of Earth Sciences \& Environmental Engineering (SESE) and International Environmental Research Institute (IERI), Gwangju Institute of Science and Technology (GIST), Gwangju 61005, Republic of Korea. 
whereas elevated levels of $\mathrm{Cu}$ in soils are known to have health risk to animals, plants, and humans [1-3]. In most developing countries, such as Tanzania, the aspects of occurrence, distribution, effect, and control of these contaminants are not adequately studied. Communities in most developing countries experience first-hand effects of environmental pollution because of the lack of skilled experts and state-of-the-art technology to deal with the pollutants [4]. Poor rural people who live next to mining facilities or next to processing/refinery industries are usually exposed to high levels of toxic ion pollution [5]. Major human exposure pathways to environmental pollutants include oral (via food and drinking water), nasal (via inhalation) and dermal (through skin contact). The use of biological agro-industrial wastes as a way to decontaminate environmental matrices is an economically feasible approach that can be applied by poor communities to combat toxic ions [6-10].

The biosorption process uses biomass either as living cells e.g. in the form of bacteria or as dead lignocellulosic materials to immobilize environmental pollutants. Application of dead biomass for water treatment is mostly preferred because it is cheaper compared to living biomass systems. Cost-effectiveness related to the application of dead biomass is brought about because dead biomass does not require culture conditioning, nor does it require any nutrient supply. Furthermore, processing and handling of dead biomass in the form of industrial or agricultural wastes is simpler, easier and less time consuming than systems that involve living biomass [11]. It is mainly these and other factors that render the application of agro-industrial wastes and byproducts (AIWBPs) for water and wastewater treatment to be both eco-friendly and economical.

Many researchers modify lignocellulose-based materials to enhance their sorption capacities [12-14]. Biosorbents can be applied in raw form, with size reduction as the only modification strategy. When raw sorbents cannot achieve desirable removal efficiencies and/or application in its raw form or causes secondary pollution, their modification becomes inevitable. Lignocellulosic material modification can be divided into two major types-physical and chemical. Physical or mechanical material modification techniques may include pyrolysis, lyophilization, cutting, autoclaving, steaming, thermal/freeze drying, grinding, etc. Chemical modification of materials used for biosorption may include pretreatment using chemical agents such as acids; alkalis; organic solvents; and other agents like $\mathrm{KOH}, \mathrm{ZnCl}, \mathrm{NaCl}, \mathrm{H}_{2} \mathrm{O}_{2}, \mathrm{Na}_{2} \mathrm{CO}_{3}$, etc. [15]. Modification of sorbents, however, may add to the costs involved and may also render the biosorbents unsuitable to the untrained user because some techniques used in modification are highly sophisticated. Therefore, the use of unmodified (or moderately-modified) biosorbents may offer a more cost-effective approach and ease of applicability for removing toxic chemicals compared to the use of their fully-modified counterparts.

Lead is a highly toxic environmental pollutant. High and chronic intake of $\mathrm{Pb}$ has neurotoxicity effects in infants and children and is known to cause cognitive disabilities [16, 17]. There are several anthropogenic sources of $\mathrm{Pb}$ including wall paints (esp. in old homes), polluted water, $\mathrm{Pb}$-containing foods, Pb-polluted soils, plastics, leaded gasoline, and cosmetics. Because of its non-biodegradability characteristics, $\mathrm{Pb}$ is ranked as one of the most persistent environmental toxins [18]. Application of the usual water and wastewater treatment methods through reverse osmosis, filtration, flocculation, coagulation, and sedimentation for $\mathrm{Pb}$ removal is less sustainable due to production of large amounts of biological and chemical sludge. These conventional methods, mentioned above, also consume a lot of energy and are susceptible to the formation of secondary pollution e.g. formation of metal hydroxides [19]. Moreover, when $\mathrm{Pb}$ is present in aqueous solution at very low levels (e.g. $<5 \mathrm{ppb}$ ), the conventional water and wastewater treatment methods can remove it but at relatively higher costs. It is important, therefore, to study other techniques such as biosorption that can efficiently remove $\mathrm{Pb}$ from water howbeit at a relatively lower cost.

Biosorption modelling can give researchers insights of the mechanisms involved in the adsorption process. Modelling of biosorption can also tell something about the characteristics of the biosorbents e.g. homogenous vs. heterogenous biosorbent surface. Modelling results may also indicate sorption capacities tenable to the biosorbent unique characteristics. The application of AIWBPs through isotherm modelling of the $\mathrm{Pb}$ biosorption process was investigated in a recent study [11]. The aim of the present study was to apply different kinetic models e.g. pseudofirst- and pseudo-second-order model to elucidate timedependency behavior of $\mathrm{Pb}$ biosorption. Furthermore, this work investigated how material modification influences sorption capacities at different reaction times.

\section{Materials and methods}

\subsection{Raw materials}

Corn (Zea mays) hulls and rice (Oryza sativa) husks was obtained from local millers in Arusha, Tanzania. Usually, local millers remove hulls (pericarps) from dried corn kernels before corn milling. Hulls and husks are usually disposed of as waste because of their low or lack of financial value. The hulls and husks were washed in the laboratory several times using deionized water (DIW) to remove extraneous contamination. Washing was done until the 
water used for cleaning became clear and transparent. To remove moisture, corn hulls and rice husks were then transferred to the oven and dried for $48 \mathrm{~h}$ at $120^{\circ} \mathrm{C}$. Dry hulls and husks were ground and sieved through a 35 -fraction mesh.

\subsection{Preparation of biochars}

Ground and sieved hull and husk materials were pyrolyzed under nitrogen flow of $100 \mathrm{~cm}^{3} / \mathrm{min}$ in a tube furnace (J-FCA Model, JISICO, South Korea) at $500{ }^{\circ} \mathrm{C}$ for an hour followed by cooling. Because pyrolysis caused the raw hull and husk materials to be compacted, the prepared biochars were ground using a motor and pestle to obtain fine biochar particles. The ground biochars were sieved, placed in conical tubes, labelled, and kept in a well-sealed desiccator for future use.

\subsection{Biochar activation}

Raw biosorbents' efficiency may be significantly improved not only thermally, through pyrolysis, but also chemically by use of activating agents [20]. Features such as pore volume, surface functional groups and even surface area may improve as a result chemical treatment on the biochars. The corn hull and rice husk biochars used in the present study were treated with $\mathrm{KOH}$ and $\mathrm{ZnCl}_{2}$. Details on biochar:chemical agent ratios and the entire activation procedure may be found in Rwiza et al. [11]. When the activation process was completed, each biochar category was named using the following codes: (1) $\mathrm{CH}=$ ground corn hulls; (2) $\mathrm{RH}=$ ground rice husks; (3) $\mathrm{CHB}=$ pre-activated corn hull biochars; (4) $\mathrm{RHB}=$ pre-activated rice husk biochars; (5) $\mathrm{Zn}-\mathrm{CHB}=$ corn hull biochars treated with $\mathrm{ZnCl}_{2}$; (6) $\mathrm{Zn}-\mathrm{RHB}=$ rice husk biochars treated with $\mathrm{ZnCl}_{2}$; (7) $\mathrm{KOH}-\mathrm{CHB}=$ corn hull biochars treated with $\mathrm{KOH}$; and (8) $\mathrm{KOH}-\mathrm{RHB}=$ rice husk biochars treated with $\mathrm{KOH}$.

\subsection{Materials characterization}

To determine the materials surface area, $\mathrm{N}_{2}$ sorption desorption isotherms at $-196{ }^{\circ} \mathrm{C}$ was performed using a sorption analyzer (MicroMetrics ASAP 2020 HV, GA, USA). Before gas adsorption, all samples were degassed for $6 \mathrm{~h}$ at $120^{\circ} \mathrm{C}$. After gas adsorption measurements, a standard Brunauer-Emmett-Teller (BET) was used for the calculation of surface area, pore volume and diameter.

The surface functional characteristics of the materials were measured using an FTIR machine (Model iS10, Thermo-NICOLET, Germany), attached with an attenuated total reflectance (ATR) accessory. Standard procedures such as fine-grinding and drying for $10 \mathrm{~h}$ were followed prior to taking the FTIR measurements. The wavenumber region for FTIR were in the region between 4000 and $400 \mathrm{~cm}^{-1}$. Surface morphological features were determined using a field emission scanning electron microscope (FE-SEM: HITACHI S-4700, Japan). Furthermore, point of zero charge $\left(\mathrm{pH}_{\mathrm{PZC}}\right)$ values were determined using a method as explained in a previous study [11].

\subsection{Kinetic modelling and contact time}

For the kinetics study, a series of $250 \mathrm{~mL}$ Erlenmeyer flasks with $200 \mathrm{~mL} \mathrm{~Pb}{ }^{2+}$ solution was used in which $1 \mathrm{~g} / \mathrm{L}$ of each biosorbent was added. The initial $\mathrm{Pb}^{2+}$ concentration was $100 \mathrm{mg} / \mathrm{L}$ at $\mathrm{pH}$ 5.0, which was adjusted using $0.1 \mathrm{M} \mathrm{HCl}$ and $\mathrm{NaOH}$ solution. Prior to conducting contact time experiments the biosorbents' removal efficiencies were tested at a $\mathrm{pH}$ range of 2-9. A mean solution $\mathrm{pH}=5$ was associated with the highest $\mathrm{Pb}^{2+}$ removal. The sorbate-sorbent solution mixture was agitated at $200 \mathrm{rpm}$ in a shaking incubator and a $1 \mathrm{~mL}$ sample was taken after every $5 \mathrm{~min}$ for a duration of $60 \mathrm{~min}$. The collected aliquot was diluted, acidified and kept in a refrigerator at $\sim 4{ }^{\circ} \mathrm{C}$ until analysis by ICP-OES. Two kinetic models were applied to the experimental data: the Lagergren pseudo-first-order model (Eq. 1) and the pseudo-second-order model (Eq. 2) as follows:

$\ln \left(q_{e}-q_{t}\right)=\ln q_{e}-k_{1} \times t$

$\frac{t}{q_{t}}=\frac{1}{k_{2} \times q_{e}^{2}}+\frac{1}{q_{e}} \times t$

where $q_{t}$ is sorption capacity $(\mathrm{mg} / \mathrm{g})$ at time $t(\mathrm{~min}) ; q_{e}$ is the equilibrium sorption capacity $(\mathrm{mg} / \mathrm{g}) ; k_{1}\left(\mathrm{~min}^{-1}\right)$ and $k_{2}(\mathrm{~g} / \mathrm{mg} / \mathrm{min})$ are the pseudo-first- and pseudo-secondorder rate constants, respectively. The results obtained from kinetic and contact experiments were also used to evaluate the relationship between materials sorption capacity and contact time.

\section{Results and discussion}

\subsection{Influence of surface morphology}

Raw corn hull and rice husk material exhibited poor formation of pores as well as surface morphological features (Fig. 1a, b). However, in Fig. 1a, fibrous features and nodular structures are clearly visible. In Fig. 1b, the surface has rectangular raster-like features. These poorly developed surface structures may play some role in enhancing the sorption capacities of raw corn hulls $(\mathrm{CH})$ and raw rice husks (RH) [21]. 
Fig. 1 Scanning electron micrographs of (a) ground raw corn hulls, (b) ground raw rice husks, (c) corn hull biochars and (d) rice husk biochars used in sorption experiments in the present study

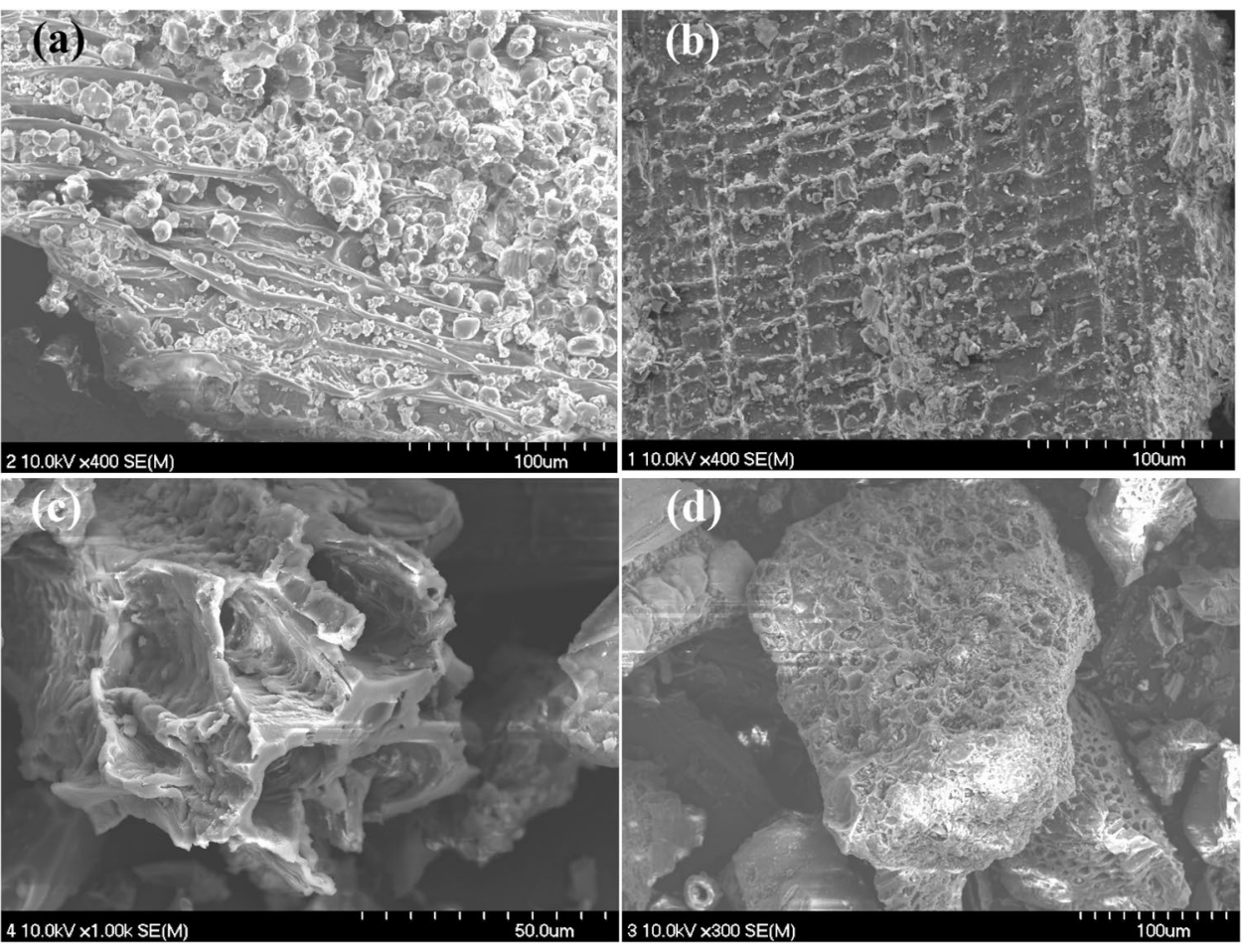

The pyrolyzed materials (Fig. 1c, d) exhibited more pore and surface morphology improvement. When compared to Fig. 1 a, b, the differences were clear. In Fig. 1c, d, clearer three-dimensional surface features were observed. On both Fig. 1c, d, pores are clearly visible but more numerous and more pronounced in Fig. $1 \mathrm{~d}$ than in Fig. 1c. This may mean that rice husk biochars are more efficient in pollutant sequestration than corn hull biochars. This was corroborated by the $\mathrm{Pb}^{2+}$ adsorption results in Fig. 5, whereby for the first $30 \mathrm{~min}$, rice husk biochar had higher sorption capacity than corn hull biochar.

During preparation of the biosorbents, the pyrolysis step was followed by the activation step in which the corn hull and rice husk biochars were activated using $\mathrm{KOH}$ and $\mathrm{ZnCl}_{2}$. The resulting SEM pictures in Fig. 2 indicate that the pores were more pronounced in the activated biosorbents than they were in the pre-activated biochars. Surface features and pores in Fig. 2a were more homogenous and well distributed compared to the surface features and pores in Fig. 2b. Compared to the inactivated biochars, the pores were more numerous and widely distributed in their activated counterparts. This may further enhance sorption capacities of the activated biochars. The SEM results corresponded well with the removal results (Fig. 5). The $\mathrm{Pb}^{2+}$ removal results indicated that corn hull biochar treated with $\mathrm{KOH}$ was the best of all biosorbents used in the present study.

Although both $\mathrm{KOH}$ and $\mathrm{ZnCl}_{2}$ were used as chemical activating agents, they affected the surface of biosorbents differently. For $\mathrm{ZnCl}_{2}$-treated biochar the well-shaped cave-like structures were less pronounced than those seen on the biochars treated with $\mathrm{KOH}$. Instead, $\mathrm{ZnCl}_{2}$-treated biochars attained an increased degree of roughness on the surface (Fig. 2c, d). However, the activation still maintained the three-dimensional structure of the biochars regardless of the type of activation agent. Also, the pores, although less pronounced were still visible. Rice husk biochar particles treated with $\mathrm{ZnCl}_{2}$ attained a sausage-like wriggled structure (Fig. 2d).

\subsection{Influence of pore size and other BET parameters}

The SEM analyses were followed by the $\mathrm{N}_{2}$ adsorption-desorption isotherm analytical procedures of the BrunauerEmmett-Teller (BET) models (Fig. 3). The isotherm indicated a typical monolayer sorption pattern. The curves were also indicative of microporous materials with relatively small surfaces whose limiting uptake may usually be governed by the accessible pore spaces rather than the available surface area [20]. According to the classification of the International Union of Pure and Applied Chemistry (IUPAC), all the eight types of materials used in the present study exhibited a Type I category of adsorbents.

The BET analysis yielded more results (Table 1). The pore diameter sizes were not greatly varied. Pore diameter sizes ranged from 1.72 to $1.87 \mathrm{~nm}$. According to the IUPAC delineation, all the sorbents in the present study fell in the microporous range category i.e. pore diameter 
Fig. 2 SEM images of (a) corn hull biochars treated with $\mathrm{KOH}$, (b) rice husk biochars treated with $\mathrm{KOH}$, (c) $\mathrm{ZnCl}_{2}$-treated corn hull biochars and (d) $\mathrm{ZnCl}_{2}$-treated rice husk biochars
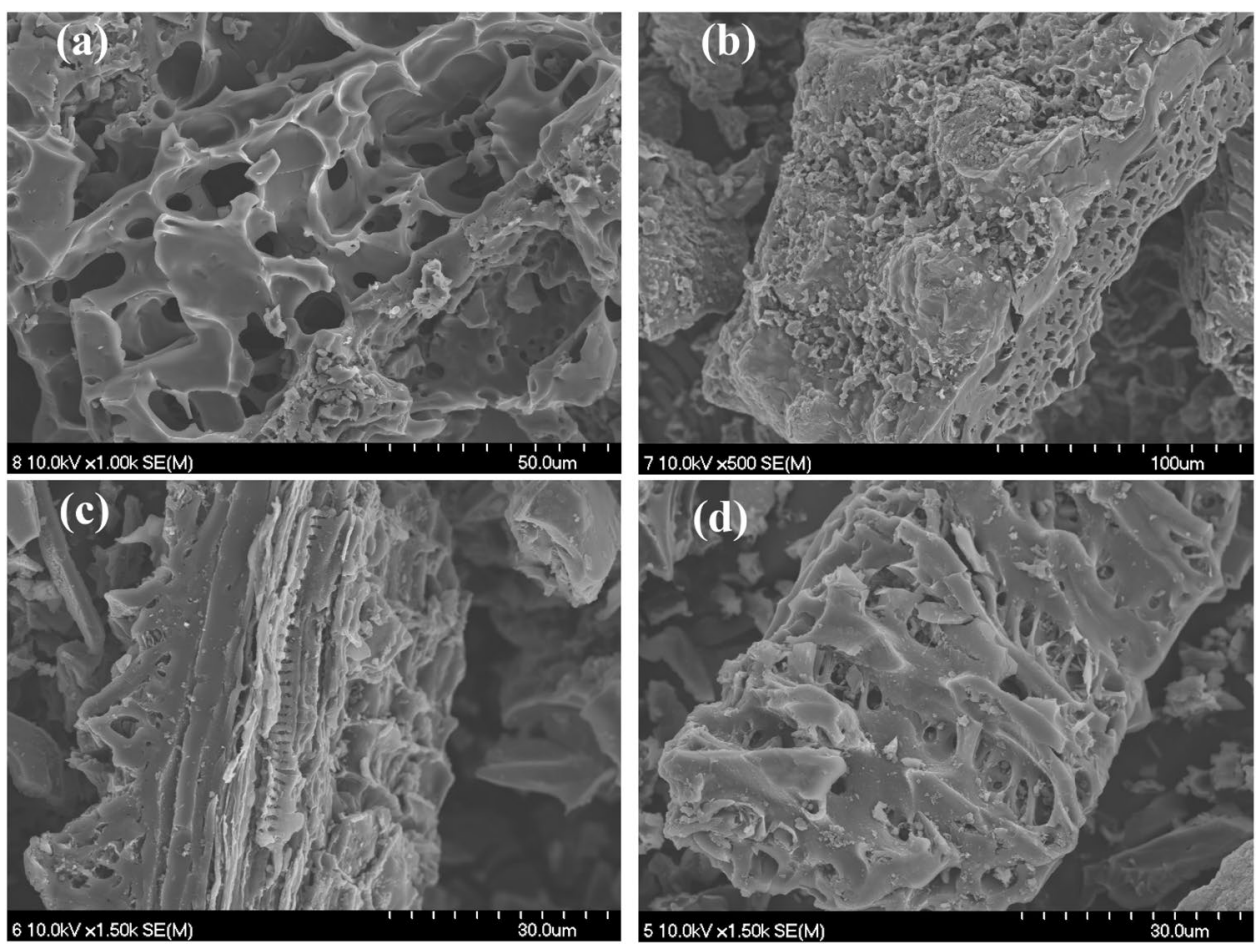
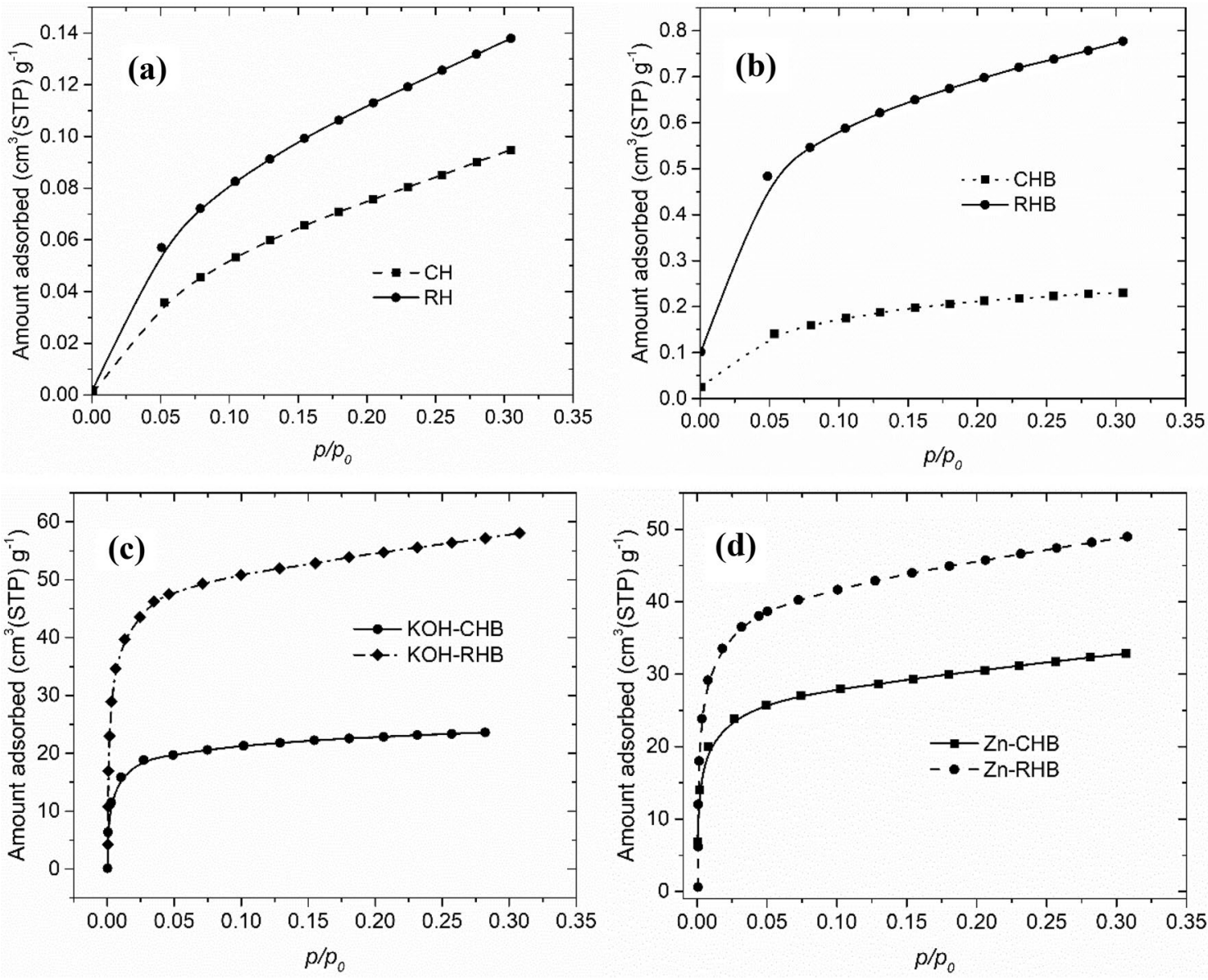

Fig. 3 Brunauer-Emmett-Teller (BET) $\mathrm{N}_{2}$ adsorption-desorption curves for (a) raw corn hulls and rice husks, (b) corn hull and rice husk biochars, (c) $\mathrm{KOH}$-treated corn hull and rice husk biochars and (d) $\mathrm{ZnCl}_{2}$-treated corn hull and rice husk biochars 
Table 1 A summary of BET characteristics of the different biosorbents used in the present study

\begin{tabular}{|c|c|c|c|c|c|}
\hline Biosorbent name & $\begin{array}{l}\text { Mean volume adsorption } \\
\text { capacity }\left(V_{m^{\prime}} \mathrm{cm}^{3} / \mathrm{g}\right)\end{array}$ & $\begin{array}{l}\text { BET surface } \\
\text { area }\left(\mathrm{m}^{2} / \mathrm{g}\right)\end{array}$ & BET constant $(C)$ & $\begin{array}{l}\text { Total pore vol- } \\
\text { ume }\left(\mathrm{cm}^{3} / \mathrm{g}\right)\end{array}$ & $\begin{array}{l}\text { Mean pore } \\
\text { diameter } \\
(\mathrm{nm})\end{array}$ \\
\hline Raw corn hulls & 0.08 & 0.33 & 14.20 & 0.0001 & 1.76 \\
\hline Raw rice husks & 0.11 & 0.47 & 18.85 & 0.0002 & 1.82 \\
\hline Corn hull biochars & 0.19 & 0.82 & 43.05 & 0.0004 & 1.75 \\
\hline Rice husk biochar & 0.59 & 2.58 & 68.09 & 0.0012 & 1.87 \\
\hline $\mathrm{KOH}$-treated corn hull biochars & 19.47 & 84.75 & 520.12 & 0.0365 & 1.72 \\
\hline $\mathrm{KOH}$-treated rice husk biochars & 46.78 & 203.62 & 490.55 & 0.0898 & 1.76 \\
\hline $\mathrm{ZnCl}_{2}$-treated corn hull biochars & 24.95 & 108.58 & 910.32 & 0.0508 & 1.87 \\
\hline $\mathrm{ZnCl}_{2}$-treated rice husk biochars & 37.95 & 165.17 & 439.03 & 0.0757 & 1.83 \\
\hline
\end{tabular}

of $<2.0 \mathrm{~nm}$. The BET curves in Fig. 3 suggest a monolayer adsorption pattern that fits the Langmuir adsorption. Most of these eight materials were found to follow the Langmuir monolayer adsorption [11]. The BET results in the present study indicated that: (1) raw rice husk was a better adsorbent than raw corn hull, (2) rice husk biochars were better adsorbents that corn hull biochars, (3) $\mathrm{KOH}$-treated corn hull biochar adsorbed better than $\mathrm{KOH}$-treated rice husk biochar and, (4) $\mathrm{ZnCl}_{2}$-treated rice husk biochar performed better than $\mathrm{ZnCl}_{2}$-treated corn hull biochar. These BET results were confirmed true by the $\mathrm{Pb}^{2+}$ removal experiment (Fig. 5). However, for most of the biosorbents used in the present study, the above trend was only true in the for the initial 30 min of the removal experiments.

The values of the BET constant, $C$, are important when discussing the $\mathrm{N}_{2}$ sorption-desorption characteristics. If the value of $C \geq \sim 80$ the 'knee' of the isotherm is usually sharp and easily distinguishable. This is what was observed in Fig. 3c, d; activation of the biochar led to clear micropores that adsorbed $\mathrm{N}_{2}$ in a good monolayer fashion [22]. Values of $C<\sim 50$ the 'knee' of the isotherm cannot be distinguished as a single point on the curve. This is what was observed in Fig. 3a, b, which suggests that there was a mix of monolayer and multilayer adsorption for the raw biosorbents [22]. As $C$ gets too small, $C<2$, the isotherm could either be Type III or Type $V$ meaning that the BET method should not be applied [22]. Values of $C>\sim 150$ are generally linked to adsorption on high-energy surface sites or the filling of micropores that are narrow [22]. This was the case for all of the activated biosorbents used in the present study (Table 1).

Overall, the raw biosorbents had the smallest surface area compared to the rest of the biosorbents. The ground raw corn hulls and rice husks had 0.33 and $0.47 \mathrm{~m}^{2} / \mathrm{g}$, respectively (Table 1 ). In the present study, there was not much difference in terms of surface area between the corn hull biochars and their raw materials. Corn hull biochars had $0.82 \mathrm{~m}^{2} / \mathrm{g}$ of biochar. However, rice husk biochars had surface area 5.5 times larger than their raw materials. This may suggest that rice husk biochars had higher adsorption capacity than raw rice husks. This observation was further confirmed by $\mathrm{Pb}^{2+}$ removal experiments where the results indicated that biochars performed better than the raw biosorbents (Fig. 5). There was a dramatic increase in surface area due to material activation (Table 1). $\mathrm{KOH}$ treated corn hull biochars had surface area 250 times larger than raw ground corn hulls. Likewise, $\mathrm{KOH}$-treated rice husk biochars attained a surface area 430 times larger than raw ground rice husks and almost 80 times larger than corn husk biochars. Equally, an enormous increase in surface area of about 325 times was found by treating the corn hull biochars with $\mathrm{ZnCl}_{2}$ when compared to the raw ground corn hulls. This surface area was still appreciably high, by a factor of about 130 , when compared to the surface area of the corn hull biochars. Furthermore, when compared to their raw counterparts, rice husk biochars treated with $\mathrm{ZnCl}_{2}$ had surface area of about 350 times larger. However, the results from this study indicate that treatment with $\mathrm{KOH}$ had a better effect on surface area enlargement than treatment with $\mathrm{ZnCl}_{2}$. A similar trend was observed in terms of the mean volume $\mathrm{N}_{2}$ adsorption capacity of the biosorbents (Table 1). The high surface area values further translated into the highest adsorption capacity values attained by the activated biosorbents as indicated by the $\mathrm{Pb}^{2+}$ removal results in Fig. 5 .

\subsection{Influence of surface functional groups}

For all the eight biosorbents, Fourier Transform-Infrared (FTIR) spectra results were found (Fig. 4). For the raw corn hull samples, there was a broad and strong $-\mathrm{OH}$ peak at around $3300 \mathrm{~cm}^{-1}$ (Fig. 4a). This peak was absent in the corn hull biochar samples. Probably the $-\mathrm{OH}$ functional group was due to moisture in the raw corn hull samples and disappeared as a result of pyrolysis. At around $2900 \mathrm{~cm}^{-1}$ (Fig. 4a), a sharp and strong peak was observed 

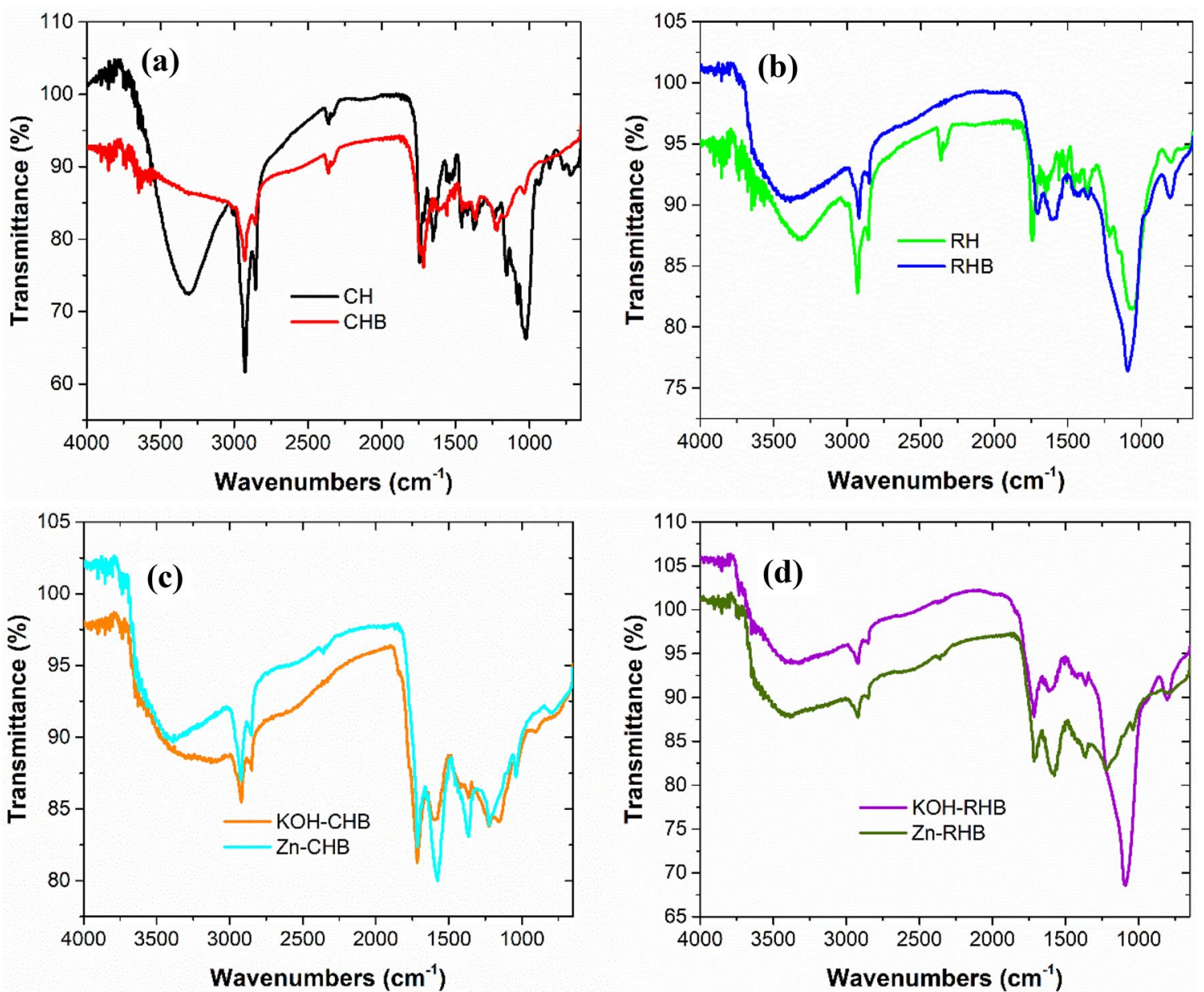

Fig. 4 Comparative progression of FTIR spectra from (a) raw corn hulls vs. corn hull biochars, (b) raw rice husks vs. rice husk biochars, (c) $\mathrm{KOH}$-treated corn hull biochars vs. $\mathrm{ZnCl}_{2}$-treated corn hull biochars to (d) $\mathrm{KOH}$-treated rice husk biochars vs. $\mathrm{ZnCl}_{2}$-treated rice husk biochars

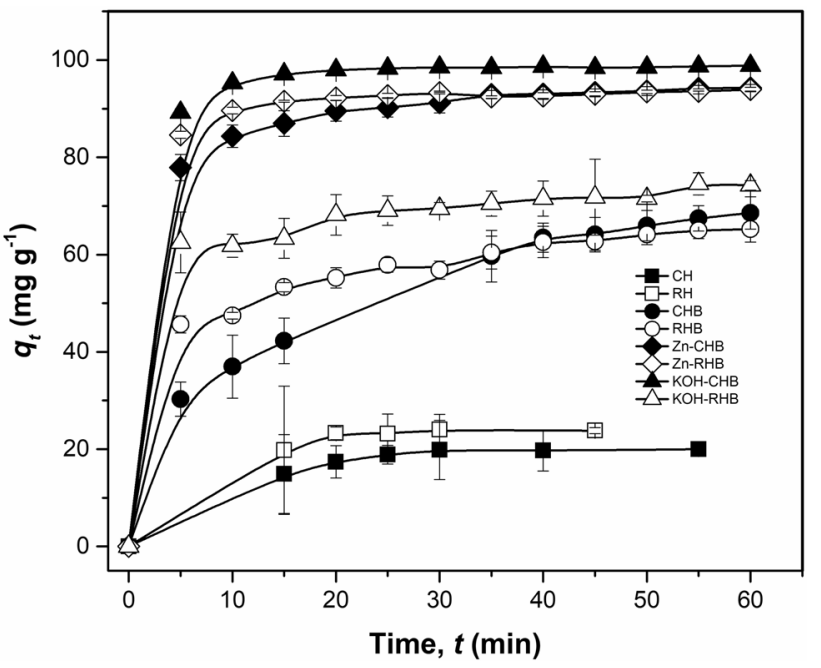

Fig. 5 The effect of contact time on the removal capacity of $\mathrm{Pb}^{2+}$ from solution using the synthesized biosorbents. Initial $\mathrm{pH}: 5.0$, initial $\mathrm{Pb}^{2+}$ conc.: $100 \mathrm{mg} / \mathrm{L}$, and $T=298 \mathrm{~K}$ that is linked to $\mathrm{C}-\mathrm{H}$ bond. This peak was stronger in the raw corn hull samples and weaker in the corn hull biochars. Sharp but very weak signals resembling the $\mathrm{C} \equiv \mathrm{C}$ or $\mathrm{C} \equiv \mathrm{N}$ were observed at around $2400 \mathrm{~cm}^{-1}$ for both raw corn hulls and corn hull biochars (Fig. 4a). Weak $\mathrm{C}=\mathrm{C}$ and $\mathrm{C}=\mathrm{O}$ peaks were observed in the raw corn hull samples at around $1600-1750 \mathrm{~cm}^{-1}$ region (Fig. 4a). These were also observed in the corn hull biochar samples. At around $1000 \mathrm{~cm}^{-1}$ a sharp and strong signal associated with ester groups was observed in the raw corn hull samples (Fig. 4a), but it was weak in the corn hull biochar samples. The ester groups were probably lost through volatilization during pyrolysis [23].

A comparison between raw rice husk samples and rice husk biochars (Fig. 4b) indicated that in the region between 1850 and $3570 \mathrm{~cm}^{-1}$ the picture is relatively similar to what was observed in the raw corn hull and corn hull biochar samples. The difference is that in Fig. $4 b$, the $-\mathrm{OH}$ stretch intensity was minimized and broadened in the native biosorbents. Also, even after pyrolysis the rice husk 
biochar retained a broad but weak $-\mathrm{OH}$ stretch. Another difference was found in the triple bond region of $C \equiv C$ and $\mathrm{C} \equiv \mathrm{N}$ where the native rice husk samples had a peak at $2360 \mathrm{~cm}^{-1}$ but this peak was lost after pyrolysis to form rice husk biochars. In the fingerprint region, strong peaks that could correspond to aromatic $\mathrm{C}=\mathrm{C}$, acyl $\mathrm{C}-\mathrm{O}$ or ester groups were found in wavenumbers between 1000 and $1200 \mathrm{~cm}^{-1}$ [24].

The two spectra for $\mathrm{KOH}$ - and $\mathrm{ZnCl}_{2}$-treated corn hull biochars (Fig. 4c) were well superimposed and had regions that were more similar than they were different. However, there were slight differences between the chemically treated corn hull biochars and their precursors. For instance, the $-\mathrm{OH}$ stretch in the native corn hulls was sharper and stronger than it was in chemically treated biochars. The $-\mathrm{OH}$ stretch in both the chemically treated biochars are broader and weaker. Furthermore, the $-\mathrm{OH}$ stretch was lost during pyrolysis of the rice hulls but treatment with activation agents restored the $-\mathrm{OH}$ stretch. Additionally, the peaks corresponding to $\mathrm{C}=\mathrm{C}$ and $\mathrm{C}=\mathrm{O}$ bends were stronger in chemically modified corn hull biochars compared to their precursors. A similar trend was observed for the chemically modified rice husk biochars. However, $\mathrm{KOH}$-treated rice husk biochar had a clear, sharp and very strong peak at around $1000 \mathrm{~cm}^{-1}$ (Fig. 4d), which could be indicative of aromaticity formation in the materials [25]. Furthermore, $C \equiv C$ and $C \equiv N$ peaks with a positional shift were observed at around $2350 \mathrm{~cm}^{-1}$ [26]. Usually, these peaks would be formed at around $2270-2100 \mathrm{~cm}^{-1}$. The positional shift of the peaks was probably linked to molecular interactions related to hydrogen bonding in the biosorbent samples [27]. Biochars pyrolyzed at temperatures $\geq 400{ }^{\circ} \mathrm{C}$ are known to form aromatic and carboxyl surface functional groups [28]. Esterification, carboxylation, and aromaticity of biochars have been associated with improved metal uptake [29].

\subsection{Effect of contact time}

In the present study, the effect of contact time in relation to sorbent type and sorption capacity was also analyzed (Fig. 5). For raw biosorbents ( $\mathrm{CH}$ and $\mathrm{RH}$ ), the sorption curves did not have a steep slope during the initial $20 \mathrm{~min}$ and their curves started to flatten at around the 25th min. Moreover, $\mathrm{RH}$ indicated a maximum $\mathrm{Pb}^{2+}$ sorption capacity of $15.71 \pm 0.26 \mathrm{mg} / \mathrm{g}$ lower than $\mathrm{CH}(19.85 \pm 0.14 \mathrm{mg} / \mathrm{g})$. High sorption capacity of the native corn hulls was probably attributable to surface fibrous and nodular nature of the $\mathrm{CH}$ material (Fig. 1a).

For the two untreated biochars, CHB and RHB (Fig. 5), the time-based sorption curves are different from what was observed in the case of the raw biosorbents. In the initial $30 \mathrm{~min}, \mathrm{~Pb}^{2+}$ sorption capacities by $\mathrm{CHB}$ were lower than the sorption capacities of RHB. At the 30th min, the sorption capacities by these two biochars became equal. At a time beyond the 30th min, $\mathrm{Pb}^{2+}$ sorption capacities by $\mathrm{CHB}$ were higher than capacities attained by RHB. This means that, within a short time span, RHB worked better than $\mathrm{CHB}$ but with longer sorption time $\mathrm{CHB}$ worked better. This was probably due to $\mathrm{Pb}^{2+}$ being mainly adsorbed on the surface of RHB followed by saturation of the surface binding sites while for $\mathrm{CHB}$ the sorption took place both on the surface and into the pores beneath the surface of the biosorbent. Therefore, it took a longer time for CHB to reach maximum sorption capacity. This was obvious in the SEM surface morphology pictures in Fig. 1c, d, where corn hull biochars exhibited deeper micropores (Fig. 1c) compared to shallower and superficial pores on RHB surface (Fig. 1d).

Biochars treated with $\mathrm{ZnCl}_{2}$ ( $\mathrm{Zn}-\mathrm{CHB}$ and $\mathrm{Zn}-\mathrm{RHB}$, Fig. 5) indicated a similar time-based $\mathrm{Pb}^{2+}$ sorption pattern. There was a dramatic increase in their sorption capacity in the initial $5 \mathrm{~min}$. Starting from a contact time of $20 \mathrm{~min}$ and afterward, there was not much change in their $\mathrm{Pb}^{2+}$ removal capacities as the binding sites began to reach saturation. For $\mathrm{Zn}-\mathrm{CHB}$, the final maximum capacity was $94.25 \pm 0.06 \mathrm{mg} / \mathrm{g}$ whereas for $\mathrm{Zn}-\mathrm{RHB}$ highest $\mathrm{Pb}^{2+}$ sorption reached is $93.64 \pm 0.26 \mathrm{mg} / \mathrm{g}$. Compared to the raw biosorbents and pre-activated biochars, $\mathrm{ZnCl}_{2}$-treated biochars produced better sorption capacity results. This was probably attributable to their higher surface area compared to both the raw biosorbents and the pre-activated biochars.

When the biochars treated with $\mathrm{KOH}$ were used to study the effect of contact time on the removal of $\mathrm{Pb}^{2+}$ from solution, interesting results emerged. Although both $\mathrm{KOH}-\mathrm{CHB}$ and $\mathrm{KOH}-\mathrm{RHB}$ had higher sorption capacities compared to the untreated biosorbents, the time-based sorption capacity pattern by $\mathrm{KOH}-\mathrm{CHB}$ was totally different from that of $\mathrm{KOH}-\mathrm{RHB}$ (Fig. 5). For $\mathrm{KOH}-\mathrm{RHB}$, there was a dramatic increase in the sorption of $\mathrm{Pb}^{2+}$ in the first $5 \mathrm{~min}$ of up to $63 \mathrm{mg} / \mathrm{g}$ followed by a slight drop in the sorption capacity at a contact time of $10 \mathrm{~min}$. After the 10-min mark, sorption capacities for $\mathrm{KOH}-\mathrm{RHB}$ started to increase gradually forming a plateau at $72.73 \pm 1.53 \mathrm{mg} / \mathrm{g}$ in the 35th $\min$. On the other hand, the sorption capacity by $\mathrm{KOH}$ CHB increased sharply to $90 \mathrm{mg} / \mathrm{g}$ in the first $5 \mathrm{~min}$ and by the 10th $\mathrm{min}$ a saturation point of $98.06 \pm 1.04 \mathrm{mg} / \mathrm{g}$ was established.

These differences in adsorption capacities between $\mathrm{KOH}-\mathrm{CHB}$ and $\mathrm{KOH}-\mathrm{RHB}$ were attributed to their differences in the point of zero charge $\left(\mathrm{pH}_{\mathrm{PZC}}\right)$ values, 5.27 and 5.93, respectively (Table $\mathrm{S} 1$ in the Supplementary Material, [11]). Because $\mathrm{KOH}-\mathrm{RHB}$ was found to have high $\mathrm{pH}_{\mathrm{PZC}}$ value, it followed that $\mathrm{KOH}-\mathrm{RHB}$ possessed a narrower $\mathrm{pH}$ range in which it could attract $\mathrm{Pb}^{2+}$ ions from water when 
Table 2 The Lagergren and pseudo-second-order model parameters for the sorption of $\mathrm{Pb}^{2+}$ onto the synthesized biosorbents

\begin{tabular}{llllllllll}
\hline Model & Parameter & \multicolumn{2}{l}{ Biosorbent } & & & & & \\
\cline { 3 - 9 } & & $\mathrm{CH}$ & $\mathrm{RH}$ & $\mathrm{CHB}$ & $\mathrm{RHB}$ & $\mathrm{Zn}-\mathrm{CHB}$ & $\mathrm{Zn}-\mathrm{RHB}$ & $\mathrm{KOH}-\mathrm{CHB}$ & $\mathrm{KOH}-\mathrm{RHB}$ \\
\hline $\begin{array}{l}\text { Pseudo-first- } \\
\text { order }\end{array}$ & $R^{2}$ & 0.74 & 0.45 & 0.81 & 0.98 & 0.99 & 0.82 & 0.71 & 0.92 \\
& $k_{1}\left(\mathrm{~min}^{-1}\right)$ & 0.01 & 0.004 & 0.09 & 0.04 & 0.05 & 0.04 & 0.04 & 0.01 \\
& $q_{e}(\mathrm{mg} / \mathrm{g})$ & 28.76 & 17.08 & 93.88 & 28.62 & 18.82 & 6.65 & 5.09 & 33.92 \\
$\begin{array}{l}\text { Pseudo-sec- } \\
\text { ond-order }\end{array}$ & $R^{2}$ & 0.99 & 0.95 & 0.99 & 0.99 & 0.99 & 0.99 & 0.99 & 0.99 \\
& $k_{2}(\mathrm{~g} / \mathrm{mg} / \mathrm{min})$ & 0.02 & 0.06 & 0.004 & 0.003 & 0.01 & 0.02 & 0.68 & 0.01 \\
& $q_{e}(\mathrm{mg} / \mathrm{g})$ & 20.86 & 16.56 & 54.17 & 69.25 & 96.34 & 94.07 & 98.33 & 75.93 \\
Experimental & $q_{e}(\mathrm{mg} / \mathrm{g})$ & $19.85 \pm 0.14$ & $15.71 \pm 0.26$ & $65.92 \pm 2.15$ & $63.94 \pm 1.23$ & $94.25 \pm 0.06$ & $93.64 \pm 0.26$ & $98.06 \pm 1.04$ & $72.73 \pm 1.53$ \\
\hline
\end{tabular}

compared to other biochars. The fast removal rate in the initial 5 min contact time was, therefore, probably attributable to the high number of binding sites initially available for binding of $\mathrm{Pb}^{2+}$ ions compared to the concentration of $\mathrm{Pb}^{2+}$. As adsorption progressed, the fraction of binding sites available for $\mathrm{Pb}^{2+}$ uptake diminished, and this led to a competition among the ions for the adsorption sites. This may have caused the observed slow-down in the rate of ion uptake as the overall interaction rate became dependent on the rate at which $\mathrm{Pb}^{2+}$ was being transported from the bulk solution to the sorbate-sorbent interface [30]. Overall and irrespective of the contact time, activated biochars attained higher sorption capacities compared to both the raw materials and the pre-activated biochars.

\subsection{Sorption kinetic studies}

In the present study, experimental results were compared to the results obtained using the Lagergren (pseudo-firstorder) and the pseudo-second-order models (Table 2) [31]. From the $R^{2}$ values, it was observed that the pseudo-second-order model fitted the data better than the pseudofirst-order model for all biosorbents. The calculated $R^{2}$ values for the pseudo-second-order model were close to unity for all biosorbents. Also, compared to the pseudofirst-order model, the pseudo-second-order model was able to predict the experimental equilibrium sorption capacities $\left(q_{e}\right)$ with a higher precision. For example, the $q_{e}$ values predicted by the pseudo-first-order and the pseudo-second order model for the sorption of $\mathrm{Pb}^{2+}$ onto $\mathrm{KOH}-\mathrm{CHB}$ were 5.09 and $98.33 \mathrm{mg} / \mathrm{g}$, respectively; the experimental value was $98.06 \pm 1.04 \mathrm{mg} / \mathrm{g}$. From these results it was observed that the pseudo-second-order model suited the experimental data better than the Lagergren model.

\subsection{Sorption mechanisms}

To elucidate the possible mechanisms of $\mathrm{Pb}^{2+}$ sorption onto the biosorbents, a Weber-Morris intraparticle diffusion model (Eq. 3) [32] was applied to the experimental data:

$q_{t}=k_{i d} \cdot p t^{1 / 2}+C$

where $q_{t}$ is sorption capacity $(\mathrm{mg} / \mathrm{g})$ at time $t(\mathrm{~min}), k_{i d}$ is the intraparticle diffusion constant ( $\mathrm{mg} / \mathrm{g} / \mathrm{min}$ ), and $C$ is a measure of the thickness of boundary layer. Results from the Weber-Morris model were plotted (Fig. 6). If a WeberMorris plot yields one straight line, then biosorption is controlled by intraparticle diffusion only [33]. However, if by plotting the data a multilinear graph is obtained, then two or more steps may be influencing the adsorption process. In the present study, plotting the experimental data using the Weber-Morris equation resulted into multilinear curves (Fig. 6). It was found that sorption of $\mathrm{Pb}^{2+}$ onto raw biosorbents ( $\mathrm{CH}$ and $\mathrm{RH}$ ) was a two-step process (Fig. 6a, b), whereas for all biochars sorption involved three steps (Fig. 6c-h). The two steps in $\mathrm{CH}$ and $\mathrm{RH}$ were probably external surface adsorption and intraparticle diffusion (Fig. 6a, b) [34]. For the case of $\mathrm{Pb}^{2+}$ adsorption onto untreated and treated biochars, all three steps-surface adsorption, intraparticle diffusion, and sorption onto active functional groups were involved (Fig. 6c-h).

The slopes, $k_{i d}$, characterize the rate of sorption i.e. the higher the $k_{\text {id }}$ value the faster the sorption rate. It is usually expected for the first phase to occur faster than the subsequent phases and this was the case for all the biosorbents used in the present study except RHB. Probably for RHB, the pore size, shape and geometry facilitated the movement of $\mathrm{Pb}^{2+}$ into the biosorbent's subsurface micropores [35]. Generally, the intercept $(C)$ values confirmed that movement from the surface to the micropores encountered an increasing boundary layer effect. Higher 
Fig. 6 The Weber-Morris intraparticle diffusion plots for $\mathrm{Pb}^{2+}$ sorption onto: (a) $\mathrm{CH}$, (b) $\mathrm{RH}$, (c) $\mathrm{CHB}$, (d) $\mathrm{RHB},(\mathbf{e}) \mathrm{Zn}-\mathrm{CHB}$, (f) $\mathrm{Zn}-\mathrm{RHB}$, (g) $\mathrm{KOH}-\mathrm{CHB}$, and (h) $\mathrm{KOH}-\mathrm{RHB}$. Black squares ( represent film diffusion step (1), open squares $(\square)$ represent intraparticle diffusion step (2), and black triangles ( $\mathbf{\Lambda}$ ) represent adsorption of $\mathrm{Pb}^{2+}$ onto active functional groups (3)
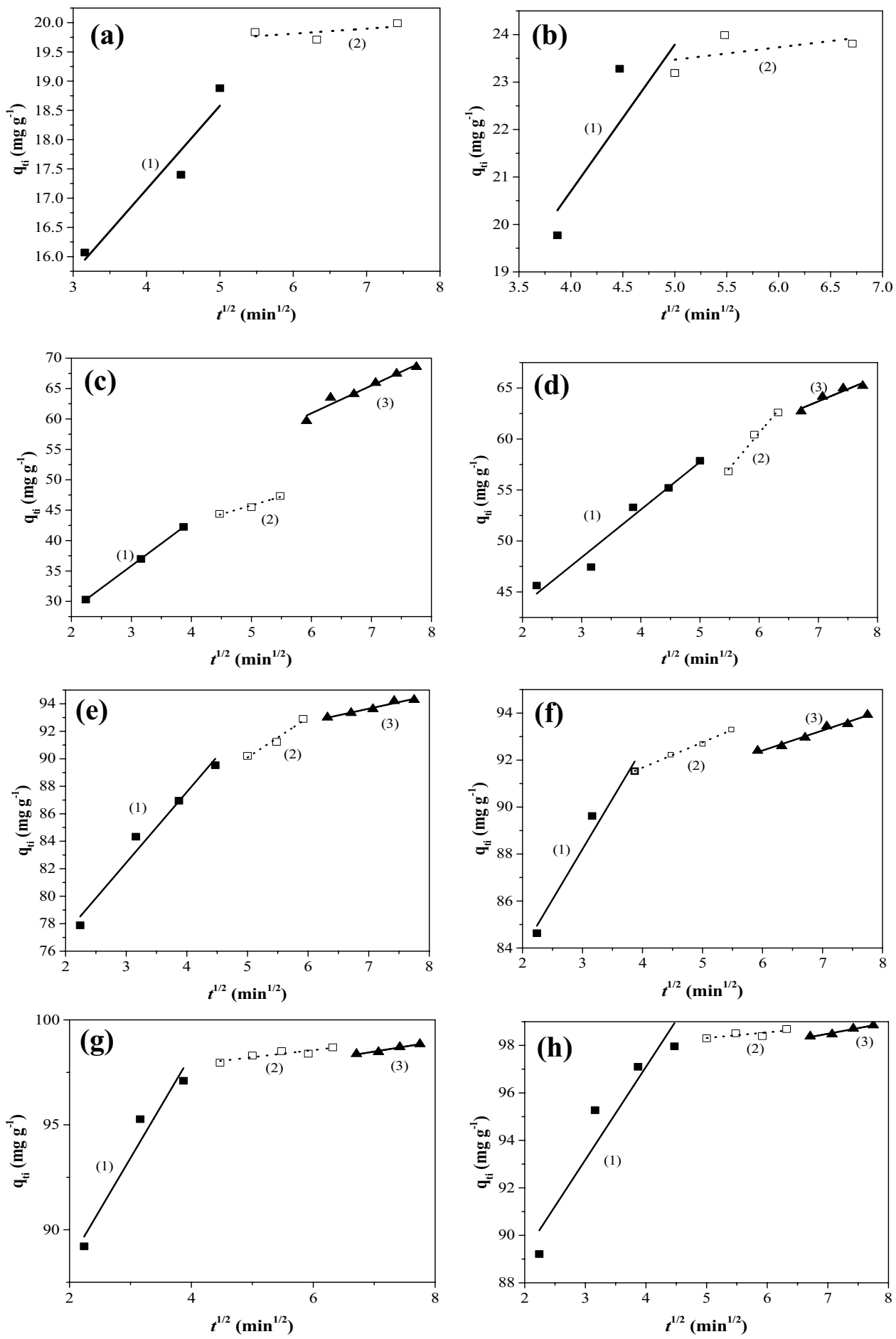

$C$ values indicate a higher boundary layer effect and vice versa. Except for RHB, the boundary layer effect increased as $\mathrm{Pb}^{2+}$ moved from phase (1) to phase (2).

Also, $k_{i d 3}$ values associated with $\mathrm{Pb}^{2+}$ transfer to the active functional groups for $\mathrm{CHB}\left(4.6 ; R^{2}=0.96\right), \mathrm{KOH}-\mathrm{CHB}$ $\left(0.47 ; R^{2}=0.97\right)$, and $\mathrm{KOH}-\mathrm{RHB}\left(0.47 ; R^{2}=0.97\right)$ were slightly higher than $k_{\text {id2 } 2}$ values of $\left(2.9 ; R^{2}=0.97\right),\left(0.34 ; R^{2}=0.83\right)$, and $\left(0.23 ; R^{2}=0.64\right)$, respectively. This indicates that $\mathrm{Pb}^{2+}$ uptake by functional groups was slightly faster than the uptake via intraparticle diffusion. This may be attributable to the availability of functional groups near the surface of these sorbents. Thus, for the raw biosorbents ( $\mathrm{CH}$ and $\mathrm{RH})$, it can be deduced that mass transport to the adsorbent surface and intraparticle diffusion, imply physisorption 
processes, were the dominant sorption mechanism. For $\mathrm{CHB}, \mathrm{KOH}-\mathrm{CHB}$, and $\mathrm{KOH}-\mathrm{RHB}$ adsorption onto surface functional groups was faster than intraparticle diffusion, indicating a dominant chemisorption mechanism. Results also indicated that $\mathrm{Pb}^{2+}$ sorption onto $\mathrm{RHB}, \mathrm{Zn}-\mathrm{CHB}$ and $\mathrm{Zn}-\mathrm{RHB}$ was dominated by physisorption processes, probably electrostatic interaction [36]. Generally, in the present study, mass transfer to the boundary layer occurred in the first $20-25 \mathrm{~min}$. This indicates high affinity of the biosorbents for $\mathrm{Pb}^{2+}$. Abdalla et al. (2019) investigated the adsorption of $\mathrm{Zn}, \mathrm{Cu}$, and $\mathrm{Pb}$ onto mushroom compost biochar using the Weber-Morris model and found a similar pattern of adsorption [37].

\section{Conclusions}

In many sub-Saharan Africa (SSA) countries, including Tanzania where the present research was conducted, agricultural wastes are freely available. In many sub-Saharan Africa cities and small towns, agricultural waste materials are usually left to rot and may lead to environmental nuisances such as foul smell and clogging of drainage systems during rainy seasons of the year. In the present study, agricultural wastes from corn and rice production was used to successfully remove lead $(\mathrm{Pb})$, one of the most notorious environmental pollutants, from water. This has threefold environmental conservation relevance: waste reuse, toxic chemical sequestration, and sustainability of agricultural systems.

Although the raw biosorbents indicated capacity to remove $\mathrm{Pb}$ from water, it was found, during the laboratory experiment, that the final water was brown. This would cause aesthetic issues to the end-user when raw corn hull and rice husk material are used for water treatment. Also, compared to the pre-activated and activated biochars; water treated by the raw corn hull sand rice husks had foul smell. Therefore, further studies are recommended on how the raw biosorbents may be used without leading to secondary contamination of the treated water.

All the materials used in the present study were in their pure form. Further studies are recommended that will hybridize the materials and examine the impacts of material hybridization on $\mathrm{Pb}^{2+}$ removal capacity. Also, the present study used wastes from only two crops. Further studies that examine the capacity of other waste materials e.g. cassava peels, tomato waste, coconut residues, and bean wastes are recommended.

Acknowledgements The authors would like to acknowledge The World Academy of Sciences (TWAS) and the Germany Research Foundation (DFG) for their support through the TWAS-DFG Cooperation Visits Programme for Postdoctoral researchers from sub-Saharan Africa. Special thanks to The Rhine-Waal University of Applied
Sciences, Germany, for hosting the visit and The Nelson Mandela African Institution of Science and Technology (NM-AIST), Tanzania, for facilitating the visit. The authors are also grateful to Gwangju Institute of Science and Technology (GIST) in South Korea, and in particular, the International Environmental Research Institute (IERI) for technical support in sample and data analyses.

Author contributions MJR: Conceptualization, methodology, data curation, writing -original draft preparation, and investigation. $K-W K$ : Supervision, software, and validation. MK: Writing, reviewing, and editing.

\section{Compliance with ethical standards}

Conflict of interest The authors declare that there are not any salient or latent conflicts of interest regarding this work.

Human and animal rights This research did not involve any human participants and/or animals.

\section{References}

1. Mujtaba Munir MA, Liu G, Yousaf B, Ali MU, Abbas Q, Ullah H (2020) Synergistic effects of biochar and processed fly ash on bioavailability, transformation and accumulation of heavy metals by maize (Zea mays L.) in coal-mining contaminated soil. Chemosphere 240:124845. https://doi.org/10.1016/j.chemo sphere.2019.124845

2. Baltas H, Sirin M, Gökbayrak E, Ozcelik AE (2020) A case study on pollution and a human health risk assessment of heavy metals in agricultural soils around Sinop province, Turkey. Chemosphere 241:125015. https://doi.org/10.1016/j.chemospher e.2019.125015

3. Gonzaga MIS, Matias MIAS, Andrade KR, Jesus AN, Cunha GC, Andrade RS, Santos JCJ (2020) Aged biochar changed copper availability and distribution among soil fractions and influenced corn seed germination in a copper-contaminated soil. Chemosphere 240:124828. https://doi.org/10.1016/j.chemospher e.2019.124828

4. Anyanwu BO, Ezejiofor AN, Igweze ZN, Orisakwe OE (2018) Heavy metal mixture exposure and effects in developing nations: an update. Toxics 6(4):65. https://doi.org/10.3390/toxic s6040065

5. Gwenzi W, Chaukura N, Mukome FND, Machado S, Nyamasoka B (2015) Biochar production and applications in sub-Saharan Africa: opportunities, constraints, risks and uncertainties. J Environ Manag 150:250-261. https://doi.org/10.1016/j.jenvm an.2014.11.027

6. Wang YY, Ji HY, Lyu HH, Liu YX, He LL, You LC, Zhou CH, Yang SM (2019) Simultaneous alleviation of Sb and Cd availability in contaminated soil and accumulation in Lolium multiflorum Lam. After amendment with Fe-Mn-Modified biochar. J Cleaner Prod 231:556-564. https://doi.org/10.1016/j.jclepro.2019.04.407

7. Wang L, Wang Y, Ma F, Tankpa V, Bai S, Guo X, Wang X (2019) Mechanisms and reutilization of modified biochar used for removal of heavy metals from wastewater: a review. Sci Total Environ 668:1298-1309. https://doi.org/10.1016/j.scito tenv.2019.03.011

8. Palansooriya KN, Ok YS, Awad YM, Lee SS, Sung JK, Koutsospyros A, Moon DH (2019) Impacts of biochar application on upland agriculture: a review. J Environ Manag 234:52-64. https://doi. org/10.1016/j.jenvman.2018.12.085 
9. Li Y, Taggart MA, McKenzie C, Zhang Z, Lu Y, Pap S, Gibb S (2019) Utilizing low-cost natural waste for the removal of pharmaceuticals from water: mechanisms, isotherms and kinetics at low concentrations. J Clean Prod 227:88-97. https://doi.org/10.1016/j. jclepro.2019.04.081

10. Dai Y, Zhang N, Xing C, Cui Q, Sun Q (2019) The adsorption, regeneration and engineering applications of biochar for removal organic pollutants: a review. Chemosphere 223:12-27. https://doi.org/10.1016/j.chemosphere.2019.01.161

11. Rwiza MJ, Oh SY, Kim KW, Kim SD (2018) Comparative sorption isotherms and removal studies for $\mathrm{Pb}$ (II) by physical and thermochemical modification of low-cost agro-wastes from Tanzania. Chemosphere 195:135-145. https://doi.org/10.1016/j.chemo sphere.2017.12.043

12. Srivastava S, Raj KR, Kardam A (2013) Efficient arsenic depollution in water using modified maize powder. Environ Chem Lett 11(1):47-53

13. Shah B, Mistry C, Shah A (2013) Seizure modeling of Pb(II) and $\mathrm{Cd}$ (II) from aqueous solution by chemically modified sugarcane bagasse fly ash: isotherms, kinetics, and column study. Environ Sci Pollut Res 20(4):2193-2209

14. Pehlivan E, Altun T, Parlayici S (2012) Modified barley straw as a potential biosorbent for removal of copper ions from aqueous solution. Food Chem 135(4):2229-2234

15. Abdolali A, Guo WS, Ngo HH, Chen SS, Nguyen NC, Tung KL (2014) Typical lignocellulosic wastes and by-products for biosorption process in water and wastewater treatment: a critical review. Bioresour Technol 160:57-66. https://doi. org/10.1016/j.biortech.2013.12.037

16. Finkelstein Y, Markowitz ME, Rosen JF (1998) Low-level leadinduced neurotoxicity in children: an update on central nervous system effects. Brain Res Rev 27(2):168-176. https://doi. org/10.1016/S0165-0173(98)00011-3

17. Skerfving S, Löfmark L, Lundh T, Mikoczy Z, Strömberg U (2015) Late effects of low blood lead concentrations in children on school performance and cognitive functions. NeuroToxicology 49:114-120. https://doi.org/10.1016/j.neuro.2015.05.009

18. Man M, Naidu R, Wong MH (2013) Persistent toxic substances released from uncontrolled e-waste recycling and actions for the future. Sci Total Environ 463-464:1133-1137. https://doi. org/10.1016/j.scitotenv.2012.07.017

19. Miretzky $\mathrm{P}$, Cirelli AF (2010) $\mathrm{Cr}(\mathrm{VI})$ and $\mathrm{Cr}$ (III) removal from aqueous solution by raw and modified lignocellulosic materials: a review. J Hazard Mater 180(1-3):1-19. https://doi.org/10.1016/j. jhazmat.2010.04.060

20. Yan L, Liu Y, Zhang Y, Liu S, Wang C, Chen W, Liu C, Chen Z, Zhang $Y(2020) \mathrm{ZnCl}_{2}$ modified biochar derived from aerobic granular sludge for developed microporosity and enhanced adsorption to tetracycline. Bioresour Technol 297:122381. https://doi. org/10.1016/j.biortech.2019.122381

21. Basu M, Guha AK, Ray L (2017) Adsorption of lead on cucumber peel. J Clean Prod 151:603-615. https://doi.org/10.1016/j.jclep ro.2017.03.028

22. Thommes M, Kaneko K, Neimark AV, Olivier JP, Rodriguez-Reinoso F, Rouquerol J, Sing KS (2015) Physisorption of gases, with special reference to the evaluation of surface area and pore size distribution (IUPAC Technical Report). Pure Appl Chem 87(9-10):1051-1069

23. Biswas B, Singh R, Kumar J, Singh R, Gupta P, Krishna BB, Bhaskar T (2018) Pyrolysis behavior of rice straw under carbon dioxide for production of bio-oil. Renew Energy 129:686-694. https:// doi.org/10.1016/j.renene.2017.04.048
24. Chia CH, Gong B, Joseph SD, Marjo CE, Munroe P, Rich AM (2012) Imaging of mineral-enriched biochar by FTIR, Raman and SEMEDX. Vib Spectrosc 62:248-257. https://doi.org/10.1016/j.vibsp ec.2012.06.006

25. Mall ID, Srivastava VC, Kumar GVA, Mishra IM (2006) Characterization and utilization of mesoporous fertilizer plant waste carbon for adsorptive removal of dyes from aqueous solution. Colloids Surf A Physicochem Eng Asp 278(1-3):175-187. https ://doi.org/10.1016/j.colsurfa.2005.12.017

26. Sanford JR, Larson RA (2020) Assessing nitrogen cycling in corncob biochar amended soil columns for application in agricultural treatment systems. Agronomy 10(7):979

27. Ryu SR, Noda I, Jung YM (2010) What is the origin of positional fluctuation of spectral features: true frequency shift or relative intensity changes of two overlapped bands? Appl Spectrosc 64(9):1017-1021. https://doi.org/10.1366/000370210792434 396

28. Clemente JS, Beauchemin S, MacKinnon T, Martin J, Johnston CT, Joern B (2017) Initial biochar properties related to the removal of $\mathrm{As}, \mathrm{Se}, \mathrm{Pb}, \mathrm{Cd}, \mathrm{Cu}, \mathrm{Ni}$, and $\mathrm{Zn}$ from an acidic suspension. Chemosphere 170:216-224. https://doi.org/10.1016/j.chemospher e.2016.11.154

29. Enaime G, Baçaoui A, Yaacoubi A, Lübken M (2020) Biochar for wastewater treatment-conversion technologies and applications. Appl Sci 10(10):3492

30. Sheha RR, El-Shazly EA (2010) Kinetics and equilibrium modeling of $\mathrm{Se}(\mathrm{IV})$ removal from aqueous solutions using metal oxides. Chem Eng J 160(1):63-71. https://doi.org/10.1016/j. cej.2010.03.004

31. Jung KW, Lee SY, Choi JW, Lee YJ (2019) A facile one-pot hydrothermal synthesis of hydroxyapatite/biochar nanocomposites: adsorption behavior and mechanisms for the removal of copper(II) from aqueous media. Chem Eng J 369:529-541. https ://doi.org/10.1016/j.cej.2019.03.102

32. Weber WJ, Morris JC (1963) Kinetics of adsorption on carbon from solution. J Sanit Eng Div 89(2):31-60

33. Kołodyńska D, Krukowska J, Thomas P (2017) Comparison of sorption and desorption studies of heavy metal ions from biochar and commercial active carbon. Chem Eng J 307:353-363. https://doi.org/10.1016/j.cej.2016.08.088

34. Ding W, Dong X, Ime IM, Gao B, Ma LQ (2014) Pyrolytic temperatures impact lead sorption mechanisms by bagasse biochars. Chemosphere 105:68-74. https://doi.org/10.1016/j.chemospher e.2013.12.042

35. Lopičić ZR, Stojanović MD, Marković SB, Milojković JV, Mihajlović ML, Kaluđerović Radoičić TS, Kijevčanin MLJ (2019) Effects of different mechanical treatments on structural changes of lignocellulosic waste biomass and subsequent $\mathrm{Cu}$ (II) removal kinetics. Arab J Chem 12(8):4091-4103. https://doi.org/10.1016/j.arabj c.2016.04.005

36. Li M, Wei D, Liu T, Liu Y, Yan L, Wei Q, Du B, Xu W (2019) EDTA functionalized magnetic biochar for $\mathrm{Pb}$ (II) removal: adsorption performance, mechanism and SVM model prediction. Sep Purif Technol 227:115696

37. Abdallah MM, Ahmad MN, Walker G, Leahy JJ, Kwapinski W (2019) Batch and continuous systems for $\mathrm{Zn}, \mathrm{Cu}$, and Pb metal ions adsorption on spent mushroom compost biochar. Ind Eng Chem Res 58(17):7296-7307. https://doi.org/10.1021/acs. iecr.9b00749

Publisher's Note Springer Nature remains neutral with regard to jurisdictional claims in published maps and institutional affiliations. 